\title{
A Comparative Study of the Phase Distribution in Carbon-Silica Hybrid Fillers for Rubber Obtained by Different Methods
}

\author{
Omar A. Al-Hartomy 1,2, Ahmed A. Al-Ghamdi', Said A. Farha Al-Said ${ }^{1,2}$, Nikolay Dishovsky ${ }^{3}$, \\ Michael B. Ward ${ }^{4}$, Petrunka Malinova3 ${ }^{3}$, Mihail Mihaylov ${ }^{3}$ \\ ${ }^{1}$ Department of Physics, Faculty of Science, King Abdulaziz University, Jeddah, Saudi Arabia \\ ${ }^{2}$ Department of Physics, Faculty of Science, University of Tabuk, Tabuk, Saudi Arabia \\ ${ }^{3}$ Department of Polymer Engineering, University of Chemical Technology and Metallurgy, Sofia, Bulgaria \\ ${ }^{4}$ LEMAS, Institute for Materials Research, SPEME, University of Leeds, Leeds, UK \\ Email: dishov@uctm.edu
}

Received 29 May 2014; revised 30 June 2014; accepted 13 July 2014

Copyright (C) 2014 by authors and Scientific Research Publishing Inc.

This work is licensed under the Creative Commons Attribution International License (CC BY).

http://creativecommons.org/licenses/by/4.0/

cc) (i)

Open Access

\begin{abstract}
Different types of carbon-silica fillers were prepared via pyrolysis-cum-water vapor of waste green tires tread and impregnation method. Dual phase fillers have been characterized by energy dispersive X-ray (EDX) spectroscopy in a scanning transmission electron microscope (STEM) or STEM-EDX. Phase distribution in hybrid fillers for rubber was investigated. The results achieved show that the conditions of obtaining influence the distribution and the location of the phases in the carbon-silica hybrid fillers as well as their most essential characteristics including specific area, oil absorption number, iodine adsorption number, ash content and others.
\end{abstract}

\section{Keywords}

Carbon Silica Hybrid Fillers, Pyrolisis, Impregnation, Filler Characterization, STEM-EDX Method

\section{Introduction}

The primary filler factors influencing elastomer reinforcement are: 1) the primary particle size or specific surface area, which, together with loading, determines the effective contact area between the filler and polymer 
matrix; 2) the structure or the degree of irregularity of the filler unit, which plays an essential role in the restrictive motion of elastomer chains under strain; 3) the surface activity, which is the predominant factor with regard to filler-filler and filler-polymer interaction [1]. The effects of filler-filler and filler-elastomer interactions on rubber reinforcement are also described [1] [2]. In order to meet the constantly growing requirements of producers, particularly those of automobile tires, in respect of the proposed fillers, the company Cabot Corporation has presented a dual phase filler of the carbon-silica type, produced by aco-fuming process [3]-[5]. With this material, the filler-filler interaction is substantially reduced due to the surface modification, and the polymer-filler interaction is enhanced by increasing the surface energy of the carbon domain of the filler and creating chemical bonding via coupling reaction between polymer chains and silanols on the silica domain. In the last years we developed successfully two different alternative methods for obtaining of hybrid fillers of carbon-silica type: by pyrolysis-cum-water vapor of worn out, waste tires and by impregnation technology. Generally, the pyrolysis of tires is described as a method for their recycling [6]-[8]. We assumed that a dual phase filler will be obtained if not standard (filled with carbon black alone) tires are subjected to pyrolysis but the so called "green" tires, containing a big quantity of silica as a filler. We assumed also that carbon phase will be formed during the pyrolysis in a result of elastomer destruction. The method is attractive, most of all, for solving an essential environmental problem and at the same time dual phase filler is being obtained whose advantages have already been described above. The experiments, carried out by us, showed that our assumption had been correct. The obtained filler was characterized and its effect on elastomeric composites on various bases including those based on natural rubber, epoxidized natural rubber, ethylene-propylene triple copolymer and others [9]-[13].

The impregnation method is one of the most widely used and popular methods for applying different phases on carriers (first of all in the production of catalysts) or for the purpose of surface and texture modification of adsorbents [14]. Using this method the second phase is deposited from the solution of so called "precursor" (the most often salts or soluble complexes) by impregnation. The impregnated substances are subjected to chemical or physical influence that may be considered like thermal activation. The method of impregnation applying of the second phase was chosen because it allowed controlled disposition of the second phase (silica) on the carbon black surface. A part of it may be retained also within the pores of the carbon black particles and in the spaces between the particles. In our previous investigations we obtained hybrid filler for rubber by deposition of zinc oxide phase on active carbon surface using the impregnation method [15]. In another previous paper [16] possibilities for application of impregnation method for obtaining of new type of reinforcing fillers for rubbers by introduction and deposition of silica phase on the particles of low active furnace carbon black, having low value of their specific surface were investigated, filler thus obtained was characterized and its influence on the properties of styrene butadiene rubber (SBR) based composites (applicable for passenger tread compounds) was studied. It is found that the mentioned above fillers increase considerably the modulus at $100 \%$ of elongation and tensile strength in comparison to standard carbon black containing composites.

One of the most important questions which interested us, was to compare what was the distribution of the phases of carbon and silica in the fillers obtained by described above different methods, to study their phase structure, to understand to what extent silica and carbon phases interpenetrated, how (and if) conditions of obtaining influenced the phase distribution and in what was the difference between these fillers. Finding answers to these questions is the purpose of present comparative study. Without a doubt, the most appropriate method for that is energy dispersive X-ray (EDX) spectroscopy in a scanning transmission electron microscope (STEM) or STEM-EDX. High angle annular dark field (HAADF) imaging in the STEM displays compositional contrast that results from different atomic number of the elements and their distribution. EDX allows one to identify what those particular elements are and their relative proportions. Initial EDX analysis usually involves the generation of an X-ray spectrum from the entire scan area of the STEM image. The Y-axis shows the counts (number of $\mathrm{X}$-rays received and processed by the detector) and the $\mathrm{X}$-axis shows the energy of those $\mathrm{X}$-rays. In addition to this EDX software can:

-keep the electron beam stationary on a spot or series of spots and generate spectra that will provide more localized elemental information;

-have the electron beam follow a line drawn on the sample image and generate a plot of the relative proportions of different elements along that line (one dimensional line scanning). Modern software now collects entire cumulative spectra from each point, so element choices can be made post acquisition;

-map the distribution and relative proportion (intensity) of different elements over the scanned area (two dimensional mapping). 


\section{Experimental}

\subsection{Materials}

2.1.1. Carbon-Silica Fillers Preparation by Pyrolysis-cum-Water Vapor of Waste Green Tires [6] [7] Two types of carbon-silica fillers (marked as CSF-1 and CSF-2 respectively) were obtained via pyrolysis-cumwater vapor of waste green tires tread (Michelin Energy 195/65 R15) in different conditions as follows:

$\mathrm{CSF}-1$ : temperature- $500^{\circ} \mathrm{C}$, water vapour concentration-40\%;

CSF-2: temperature- $700^{\circ} \mathrm{C}$, water vapour concentration-40\%.

\subsubsection{Carbon-Silica Fillers Preparation by Impregnation Technology}

Two types of carbon-silica fillers (marked as CSF-10 and CSF-20 respectively) were obtained by impregnation procedure as follows:

Industrial furnace carbon black type PM-15 (produced in Russia, which characteristics are close to those of carbon black ASTM type N 776), with specific area of $15 \mathrm{~m}^{2} / \mathrm{g}$ were used as a substratum in our investigation. Silicasol (silica content-40\%, $\mathrm{pH}-9$ and density $1.3 \mathrm{~g} / \mathrm{cm}^{3}$ ) was chosen as impregnating agent due to our idea to obtain reinforcing carbon-silica dual phase filler. Impregnation modifying of carbon black with $\mathrm{SiO}_{2}$ is accomplished by spraying with the help of an atomizer via Thin Layer Chromatography method under continuous stirring. The quantity of $\mathrm{SiO}_{2}$ solution needed for sufficient wetting of carbon black is $1.6 \mathrm{~mL} / \mathrm{g}$ carbon black. The quantity of silicasol for impregnation of carbon black is calculated preliminarily in order to be introduced the determined percentage of $\mathrm{SiO}_{2}$. The procedure of impregnation treating of carbon black is proceeding in two stages. In the first stage of synthesis, one tenth of calculated solution is diluted with distilled water in a ratio 1:10. After spraying this solution on carbon black under permanent stirring, the sample remains for 24 hours at a room temperature, and then undergoes thermal treatment for 2 hours at a temperature of $323^{\circ} \mathrm{K}-353^{\circ} \mathrm{K}$ and 2 hours at $523^{\circ} \mathrm{K}$. Second stage: the rest of solution is applied by analogical procedure and conditions. After applying the solution, carbon black stays again for 24 hours in air at a room temperature, then being treated thermally for 2 hours at a temperature of $323^{\circ} \mathrm{K}-353^{\circ} \mathrm{K}$, four hours at $425^{\circ} \mathrm{K}$ and four hours at $523^{\circ} \mathrm{K}$. The dual phase fillers obtained are of different $\mathrm{SiO}_{2}$ content, calculated as follows: CSF-10-10\% $\mathrm{SiO}_{2}, \mathrm{CSF}-20-20 \%$ $\mathrm{SiO}_{2}$.

\subsection{Methods Used for Characterization of Substratum and Carbon Silica Dual Phase Fillers}

- Iodine adsorption — in correspondence to [17].

- Oil absorption number-in correspondence to [18].

- Specific surface area-calculated by the method of BET [19].

The ash content of the carbon silica fillers obtained by impregnation technology was determined according to [20]. The ash from the fillers was studied by complete silicate analyses, weight analysis, atomic absorption spectroscopy-AAS (Perkin Elmer 5000), inductively coupled plasma-optical emission spectroscopy-ICP-OES ("Prodigy” High Dispersion ICP-OES, Teledyne Lemas Labs).

For ascertaining the distribution of carbon black and silica, the hybrid products and their physical mixture were also investigated by the method of STEM-EDX (STEM, FEI Tecnai F20, FEGTEM) operating at $200 \mathrm{kV}$ and equipped with an Energy Dispersive X-ray Analyzer (Oxford Instruments, $80 \mathrm{~mm}^{2} \mathrm{X}$-max SDD, running INCA software). One gram of powder of each sample was used for the analyses. A small amount of it was mixed with solvent and then drop onto a carbon support film using a pipette. The ratio of the Si to C counts was used as an estimate of the relative ranking of the amount of silica and carbon in certain regions in the filler aggregates.

\section{Results and Discussion}

Table 1 and Table 2 summarize the main properties of the carbon-silica fillers obtained.

Table 3 and Table 4 summarize the results of silicate analysis, AAS and ICP-OES (in \%) of ashes of the carbon-silica fillers investigated.

By comparing the results in Tables 1-4, following makes immediately an impression: 
The results for the fillers obtained by the methods developed by us differ very strongly due to the radically opposing technologies used: by pyrolysis, initial raw material used was vulcanizate (worn automobile tires), containing significant amount of silica as filler due to which their ash content is very high. The content of organic matter (carbon black) is within the limits $28 \%$ - 36\% and contents of inorganic-within $72 \%-64 \%$. The availability of some amounts of carbon black in the fillers investigated, allowed determining its iodine adsorption and oil numbers. The carbon phase occurring upon destruction of rubber in the tire in the conditions of pyrolysis-cum-water is characterized by very high values of iodine number. The iodine number reflects a "not true" surface area, because it is affected by porosity, surface impurities and surface oxidation (and oil number). Oil absorption number reflects the empty space (void volume) between the aggregates and agglomerates usually expressed as a volume of dibutylphtalate absorbed by a given amount of the filler (comparable with those of the most active furnace carbon black N220) which is indicative of high adsorption activity as regards rubber ma-

Table 1. Main properties of the carbon-silica fillers obtained by pyrolysis.

\begin{tabular}{ccc}
\hline Properties & CSF-1 & CSF-2 \\
\hline Iodine adsorption (IA), mg/g & 215 & 127 \\
Oil absorption number (OAN), mL/100g & 140 & 157 \\
Specific surface area (BET), $\mathrm{m}^{2} / \mathrm{g}$ & 116 & 108 \\
Ash content, \% & 64 & 72 \\
\hline
\end{tabular}

Table 2. Main properties of the carbon-silica fillers obtained by impregnation.

\begin{tabular}{ccc}
\hline Properties & CSF-10 & CSF-20 \\
\hline Iodine adsorption (IA), mg/g & 20 & 16 \\
Oil absorption number (OAN), $\mathrm{mL} / 100 \mathrm{~g}$ & 69 & 62 \\
Specific surface area (BET), $\mathrm{m}^{2} / \mathrm{g}$ & 31 & 48 \\
Ash content, \% & 13 & 22 \\
\hline
\end{tabular}

Table 3. Silicate analysis, AAS and ICP-OES (in \%) of the ashes of carbon-silica fillers obtained by pyrolysis.

\begin{tabular}{ccc}
\hline & $\mathrm{CSF}-1$ & $\mathrm{CSF}-2$ \\
$\mathrm{SiO}_{2}$ & 92.56 & 93.84 \\
$\mathrm{Al}_{2} \mathrm{O}_{3}$ & 0.55 & 0.55 \\
$\mathrm{CaO}$ & 0.18 & 0.14 \\
$\mathrm{MgO}$ & 0.23 & 0.12 \\
$\mathrm{Na}_{2} \mathrm{O}$ & 0.86 & 0.91 \\
$\mathrm{~K}_{2} \mathrm{O}$ & 0.08 & 0.05 \\
$\mathrm{Fe}_{2} \mathrm{O}_{3}$ & 0.46 & 0.40 \\
$\mathrm{MnO}$ & $<0.01$ & $<0.01$ \\
$\mathrm{TiO}_{2}$ & 0.02 & 0.03 \\
$\mathrm{ZnO}_{\mathrm{CuO}}$ & 3.82 & 2.8 \\
$\mathrm{PbO}_{\mathrm{NiO}}$ & 0.08 & 0.08 \\
$\mathrm{Cr}_{2} \mathrm{O}_{3}$ & 0.03 & 0.02 \\
$\mathrm{Heat} l o s s e s, 1000^{\circ} \mathrm{C}$ & $<0.01$ & $<0.01$ \\
\hline & 0.01 & $<0.01$ \\
\hline
\end{tabular}


Table 4. Silicate analysis, AAS and ICP-OES (in \%) of ashes of the carbon-silica fillers obtained by impregnation.

\begin{tabular}{|c|c|c|}
\hline & CSF-10 & CSF-20 \\
\hline $\mathrm{SiO}_{2}$ & 94.73 & 95.26 \\
\hline $\mathrm{Al}_{2} \mathrm{O}_{3}$ & 0.24 & 0.26 \\
\hline $\mathrm{CaO}$ & 0.31 & 0.22 \\
\hline $\mathrm{MgO}$ & 0.11 & 0.08 \\
\hline $\mathrm{Na}_{2} \mathrm{O}$ & 2.30 & 1.97 \\
\hline $\mathrm{K}_{2} \mathrm{O}$ & 0.35 & 0.19 \\
\hline $\mathrm{Fe}_{2} \mathrm{O}_{3}$ & 0.11 & 0.13 \\
\hline $\mathrm{MnO}$ & 0.07 & 0.01 \\
\hline $\mathrm{TiO}_{2}$ & $<0.01$ & 0.24 \\
\hline $\mathrm{ZnO}$ & $<0.01$ & $<0.01$ \\
\hline $\mathrm{CuO}$ & $<0.01$ & $<0.01$ \\
\hline $\mathrm{PbO}$ & $<0.01$ & $<0.01$ \\
\hline $\mathrm{NiO}$ & $<0.01$ & $<0.01$ \\
\hline $\mathrm{Cr}_{2} \mathrm{O}_{3}$ & $<0.01$ & $<0.01$ \\
\hline Heat losses, $1000^{\circ} \mathrm{C}$ & 1.72 & 1.61 \\
\hline
\end{tabular}

cromolecules, but also for a pronounced tendency to the formation of secondary structures-aggregates and agglomerates. The specific surface (BET nitrogen adsorption surface area shows the "total" surface area including porosity) is also high, similar to that of carbon black N220. The case with the dual phase fillers, obtained by impregnation is contrary: ash content is much lower, the inorganic matter is within the limits of $13 \%$ - $22 \%$, i.e. organic matter prevails in them (within the limits of $78 \%-87 \%$ ), iodine and oil numbers have values specific for the lowest active furnaces carbon black, which is used as a raw material. For both types of fillers, silica prevails in the ash and its content has similar percentage values, but in the ashes of pyrolysis product there is a significant amount of zinc oxide ( $3 \%-4 \%$ ), entered in the rubber mixture due to its activating action in respect of vulcanization process, while its content in the ashes of impregnation product is minimal-under $0.01 \%$. However, it is found in it higher levels of disodium oxide $(2 \%-2.3 \%)$, coming probably from silicasol, compared with pyrolysis product, where it is within the limits of $0.85 \%-0.90 \%$.

Representative HAADF images and compositional maps of the carbon silica fillers obtained by pyrolysis and impregnation are shown in Figures 1-4.

The first general impression is that carbon and $\mathrm{SiO}_{2}$ phases are much better mixed in the samples CSF- 1 and CSF-2, prepared by the pyrolysis than in samples, prepared by impregnation. Regarding the actual type of mixing, it is quite clear that both phases exist individually, i.e. discreet regions of amorphous $\mathrm{SiO}_{2}$, and of soot-like carbon. The only difference is in the degree to and scale on which the particles are mixed. The EDX maps show how the different particles were distributed. In the CSF- $1 \mathrm{SiO}_{2}$ is more evenly distributed, the aggregates are smaller than and not as well-insulated as in CSF-2, the penetration of the phases one to another is more fully. It appears that there is better mixing in CSF-1 compared to CSF-2 from the maps and if this was the case it would agree with the results from the surface area measurements. One can see from the Table 1 that indeed the surface area of CSF-1 is higher than the surface area of CSF-2. The maps create the impression that the carbon phase occupies the spaces between the aggregates of silicon dioxide, mostly with spherical morphology, which is logical, since at the time of the formation of this phase through elastomer destruction, silica exists already as a phase. We consider this a positive effect, because in this way it is hindered the formation of large silica aggregates as a result of the strong interactions "filler-filler", which is not desired. In all samples investigated carbon and silica exist as separate phases and there are not evidences for some type of chemical mixing. One can see that in them carbon and silica coexist in space, penetrating one another. Carbon and silica are found together (in the same place) all over CSF-1 and CSF-2 samples, while that penetration in CSF-1 is at a higher level and the 


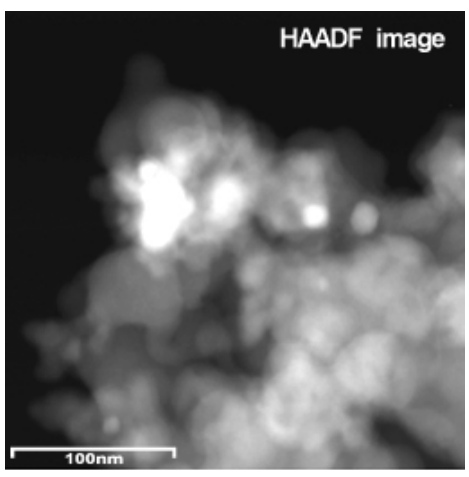

(a)

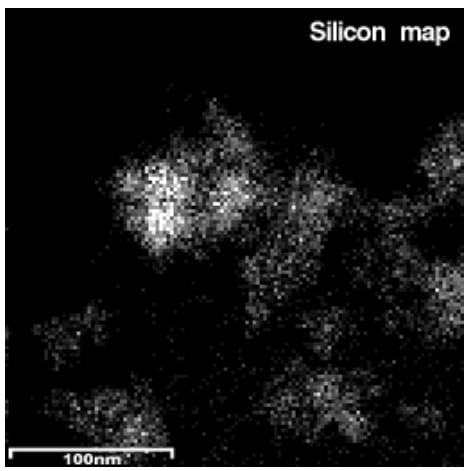

(d)

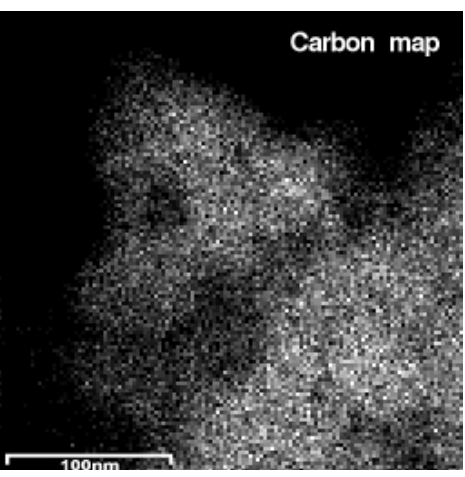

(b)

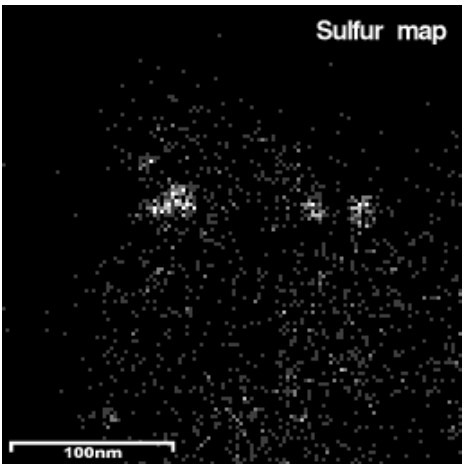

(e)

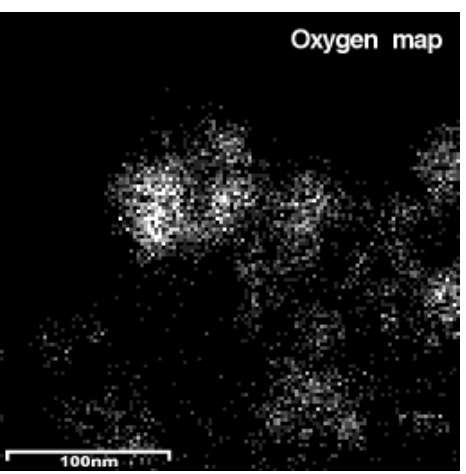

(c)

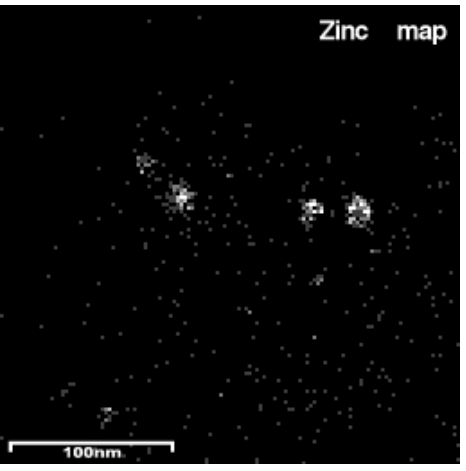

(f)

Figure 1. HAADF image (a) and compositional maps of CSF-1 (b), (c), (d), (e), (f).

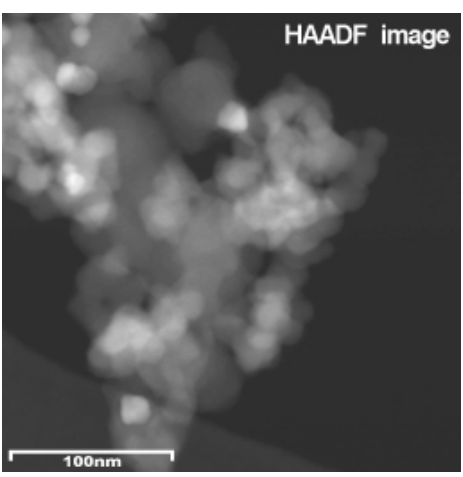

(a)

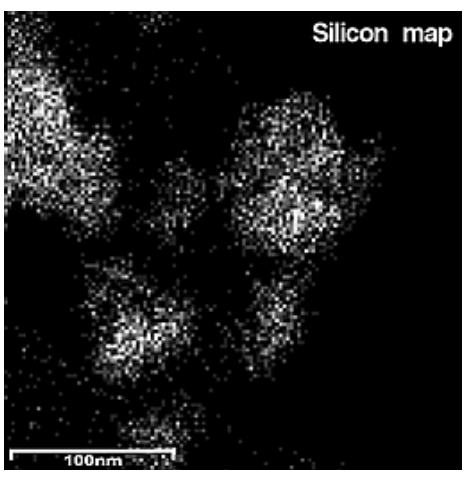

(d)

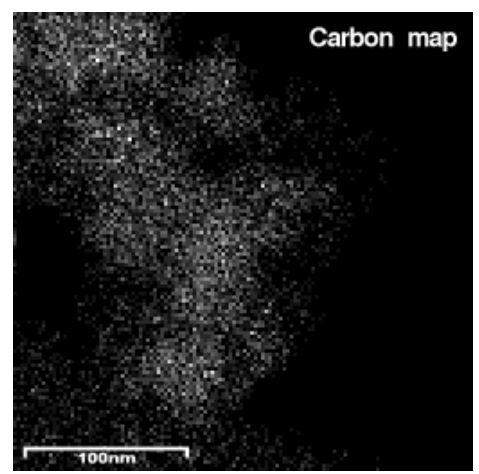

(b)

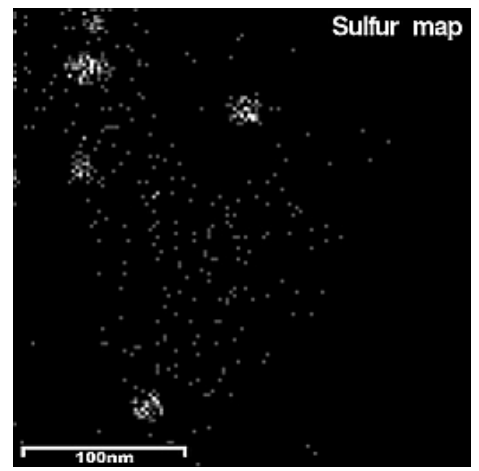

(e)

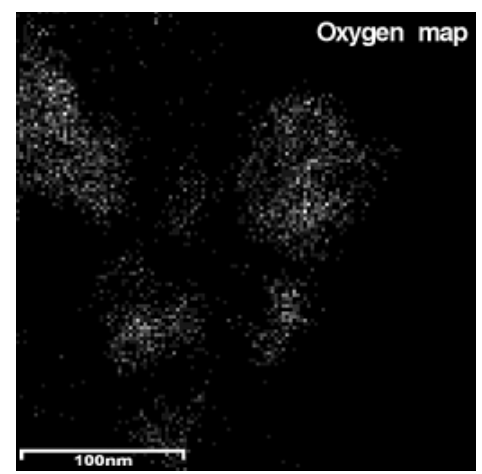

(c)

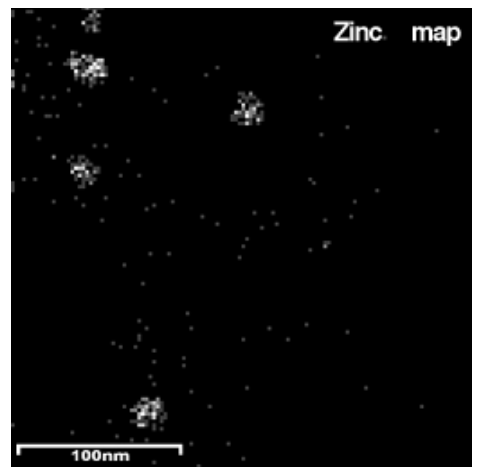

(f)

Figure 2. HAADF image (a) and compositional maps of CSF-2 (b), (c), (d), (e), (f). 


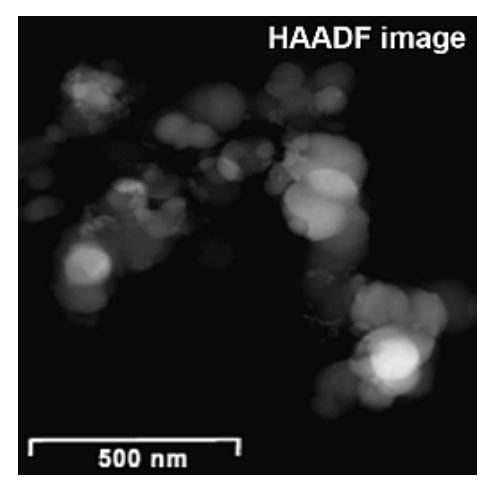

(a)

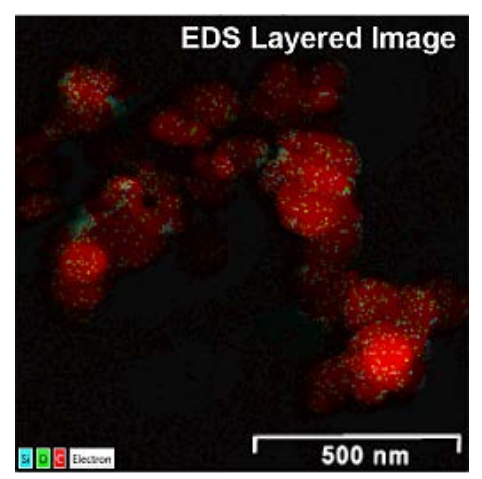

(b)

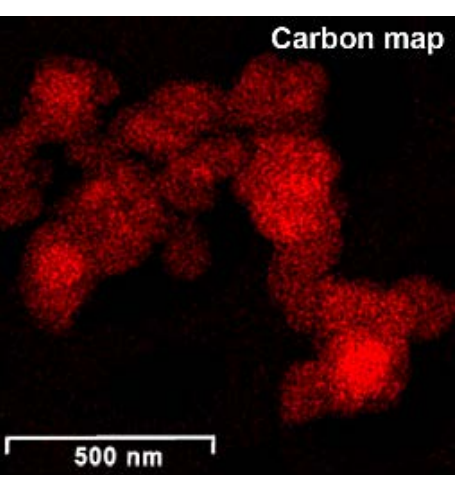

(c)

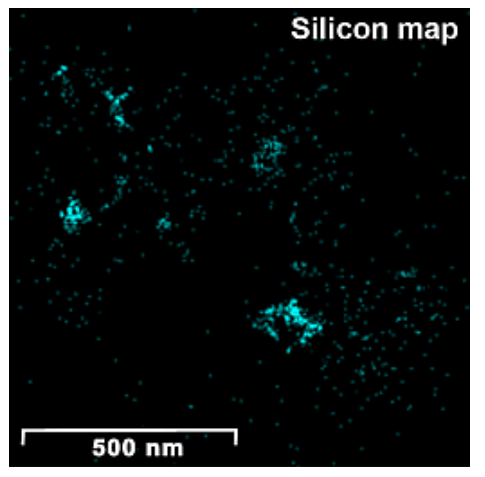

(d)

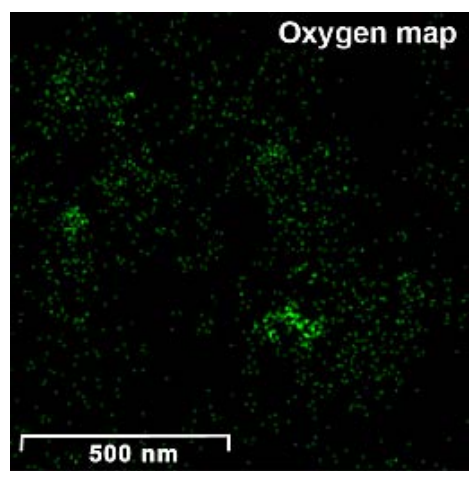

(e)

Figure 3. HAADF image and compositional maps of CSF-10.

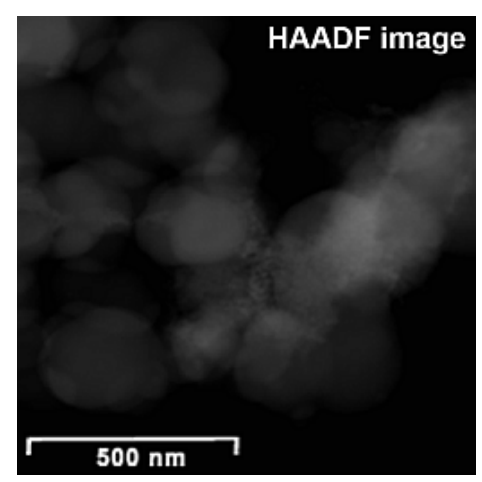

(a)

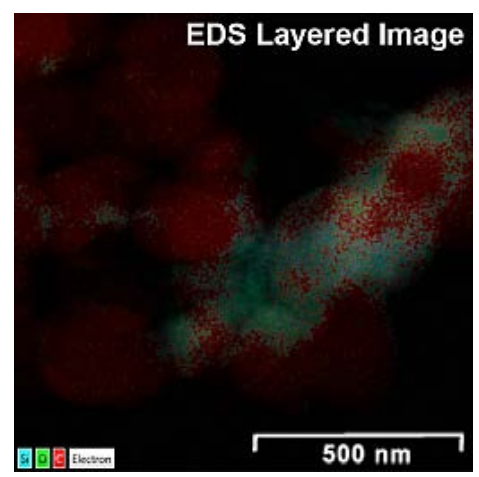

(b)

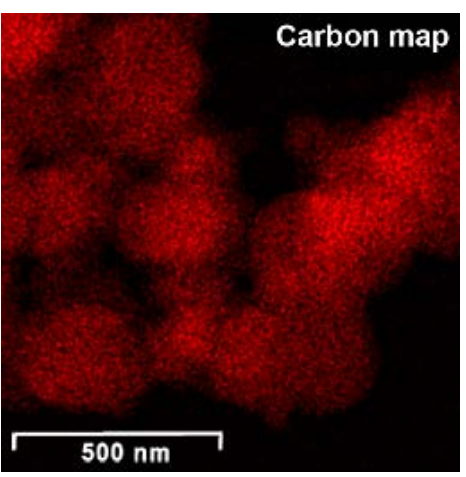

(c)

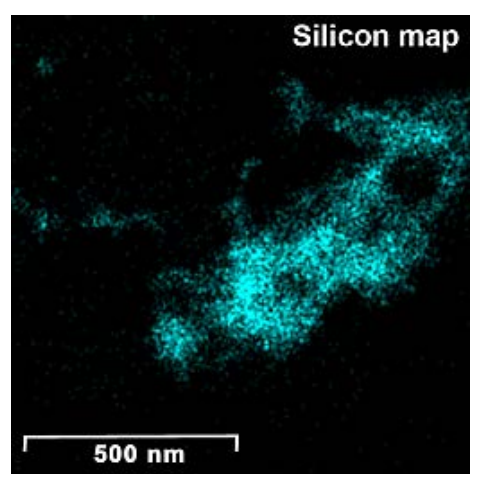

(d)

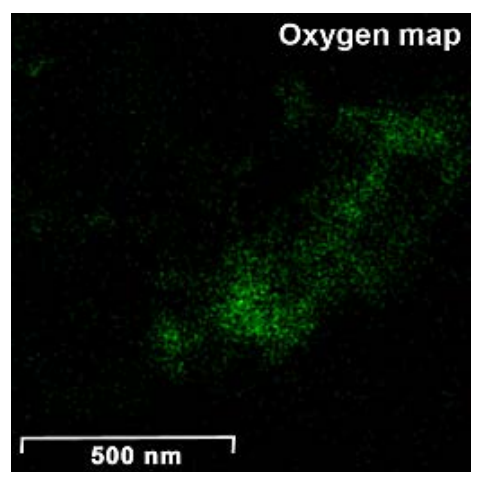

(e)

Figure 4. HAADF image and compositional maps of CSF-20. 
two phases are to be found oftener together at one and same time.

Regarding the samples obtained by impregnation, it is quite clear that both phases also exist individually, i.e. discreet regions of amorphous $\mathrm{SiO}_{2}$, and of soot-like carbon. The EDX maps show how the different particles were distributed. At a concentration of silica 10\% (sample CSF-10), it is not to observe dominant placement of both types of particles. Varieties of cluster position are observed. Silica clusters are located both outside and inside carbon black clusters but it seems that more of them are outside, especially on the surface of carbon black clusters. In the samples with 20\% concentration of silica (sample CSF-20), it is nearly not to see individual clusters of silica, particles of the latter have penetrated into the interior of the carbon black clusters. In more cases silica particles (as clusters) are inside the carbon black clusters, i.e. they are occluded, but some silica clusters are out of the carbon black clusters and are located as a coating of carbon black clusters. It seems that silica clustering is more often seen than silica coating of the carbon black clusters. According to the images, the most favorable sample is that with $10 \%$ silica. It creates the impression that the two phases are best blended. At the higher concentration (CSF-20), the better part of silica particles are located inside the carbon black clusters, which insulates them from contacts with elastomer macromolecules. That is confirmed also by the bright field TEM images of investigated samples made at different magnifications (Figures 5-8).

Indisputably the biggest difference established between hybrid fillers, obtained by both methods is the presence of zinc and sulfur in the fillers produced by pyrolysis in the form of zinc sulfide (Figure 1, Figure 2) whose presence is not found in the fillers obtained by other method. EDX spectra ascertain the availability of zinc sulphide (ZnS) in the fillers, obtained by pyrolysis (Figure 9). These spectra are taken from the three types of particles-ZnS, carbon and $\mathrm{SiO}_{2}$, available in the hybrid fillers investigated. They all have some silica in; this is contamination (apart from the $\mathrm{SiO}_{2}$ which actually has $\mathrm{Si}$ ).

We can consider the presence of $\mathrm{ZnS}$ in the hybrid fillers investigated as a by-product, result of the reaction:

$$
\mathrm{ZnO}+\mathrm{H}_{2} \mathrm{~S}=\mathrm{ZnS}+\mathrm{H}_{2} \mathrm{O}
$$

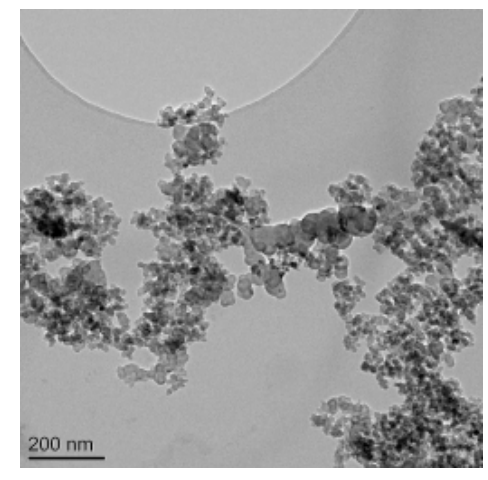

(a)

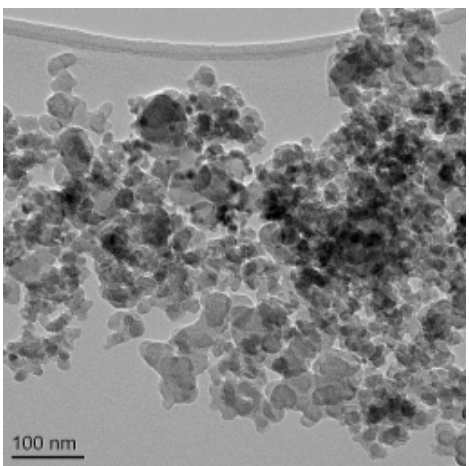

(b)

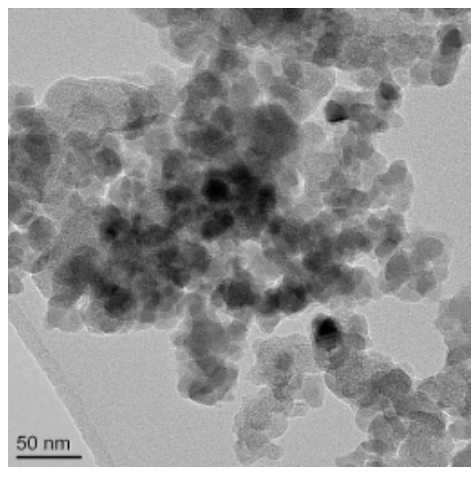

(c)

Figure 5. Bright field TEM images of CSF-1 at different magnifications.

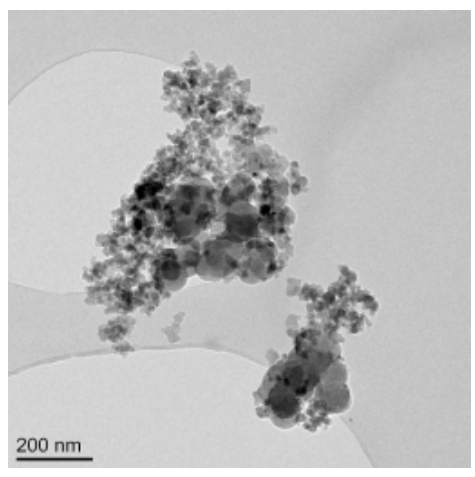

(a)

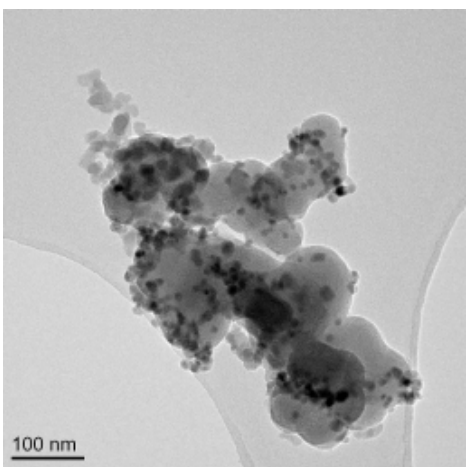

(b)

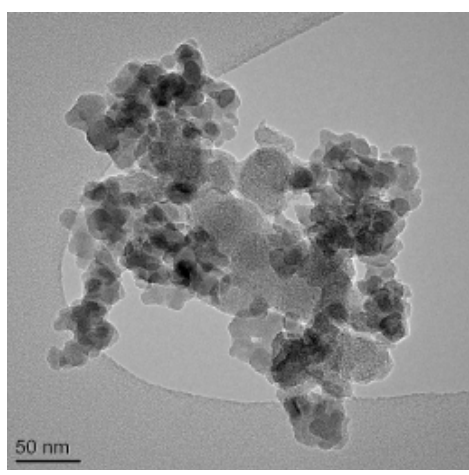

(c)

Figure 6. Bright field TEM images of CSF-2 at different magnifications. 


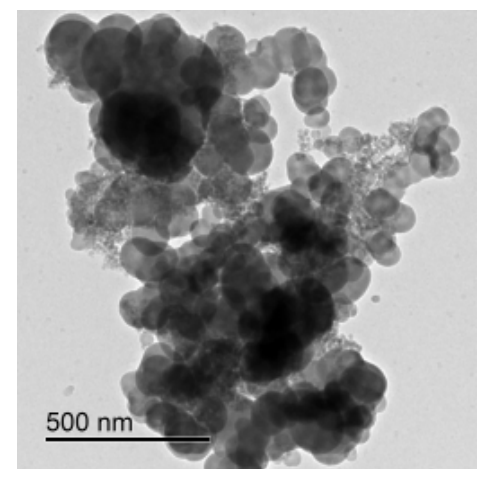

(a)

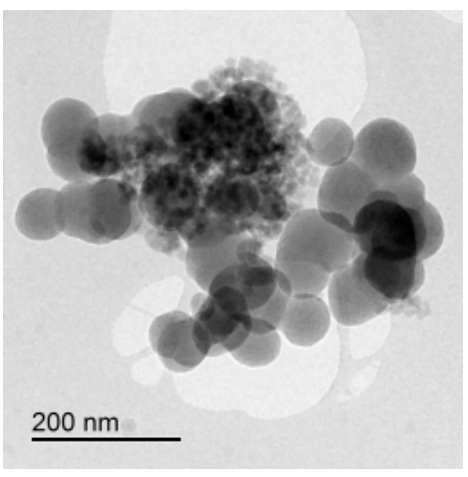

(b)

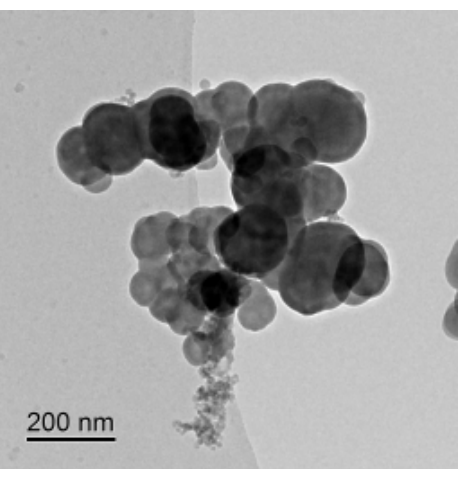

(c)

Figure 7. Bright field TEM images of CSF-10 at different magnifications.

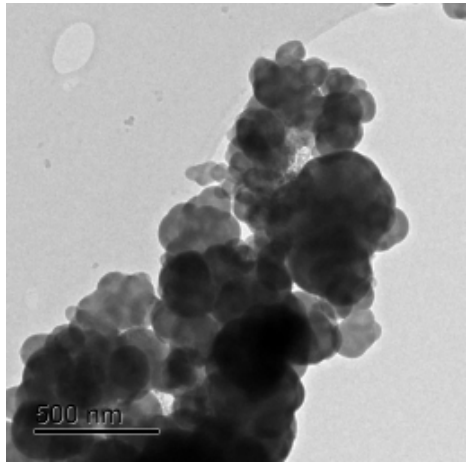

(a)

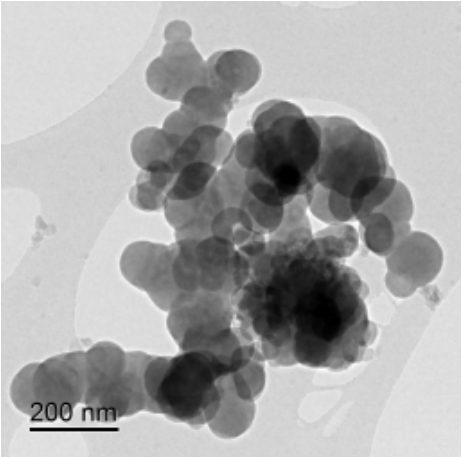

(b)

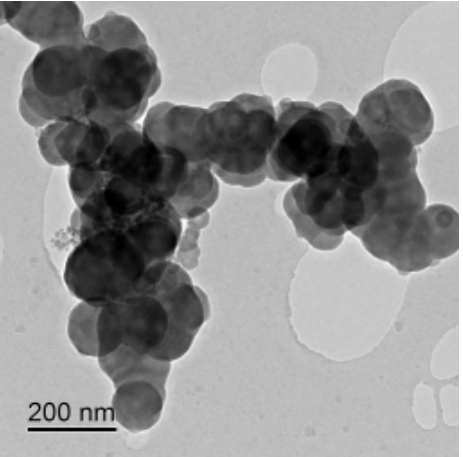

(c)

Figure 8. Bright field TEM images of CSF-20 at different magnifications.

$\mathrm{H}_{2} \mathrm{~S}$ can be produced in the filler by reacting hydrogen gas (available in the air) with molten elemental sulfur over $450^{\circ} \mathrm{C}$ [21] during process of waste tires pyrolysis, carried out at $500^{\circ} \mathrm{C}$ and $700^{\circ} \mathrm{C}$ resp. for CSF- 1 and CSF-2. Dohi and Horiuchi [22] investigating vulcanized rubber structures by energy-filtering transmission electron microscopy (EFTEM) and by high-angle annular dark field scanning transmission electron microscopy (HAADF-STEM) also observe numerous particles with the diameter of about $20 \mathrm{~nm}$, distributed in the rubber matrix, which could not be observed by conventional TEM. Further examination based on electron energy-loss spectroscopy (EELS) and energy-dispersive X-ray (EDX) analysis indicated that those particles are composed of $\mathrm{ZnS}$ clusters with the sizes of approximately $3-5 \mathrm{~nm}$. The authors consider that the particles are produced as a by-product in the vulcanization. They believe that the formation of ZnS clusters in a rubber network is one of the origins of rubber heterogeneities. There are data, available in the literature [23] that mechanical properties such as tensile and tear strength increases with increase in concentration of nano $\mathrm{ZnS}$ up to $7 \mathrm{phr}$ of loading thereafter the value decreases, whereas hardness, and flame resistance increases with the dosage of fillers. Data confirming that ZnS has a heat stabilizing activity in synthetic rubber are also available [24]. On the other hand the presence of zinc oxide in the fillers (shown in Table 2) gives grounds to suppose that when using such fillers, vulcanization of mixtures could be held with a reduced amount of zinc oxide in their composition which is very important due to the ecological reasons. It is also obvious that the conditions of pyrolysis influence practically all the characteristics of hybrid filler, as can be seen from Table 1 and Table 2. Research by STEM-EDX shows also their influence on the formation of silica aggregates, their size and placement of the carbon phase among them. It can be considered, that the conditions for obtaining of CSF-1 are more favorable from that point of view because the aggregates of the both phases with it, are not well isolated and their mutual penetration is at a higher level. Characteristics of CSF-1 and CSF-2, shown in Table 1 and Table 2 also give precedence to the first of them: its specific surface area is higher as well as iodine adsorption, ash content is lower, it contains bigger quantity of carbon phase etc.

Energy dispersive spectra on STEM of carbon black-silica filler obtained by impregnation are shown in 


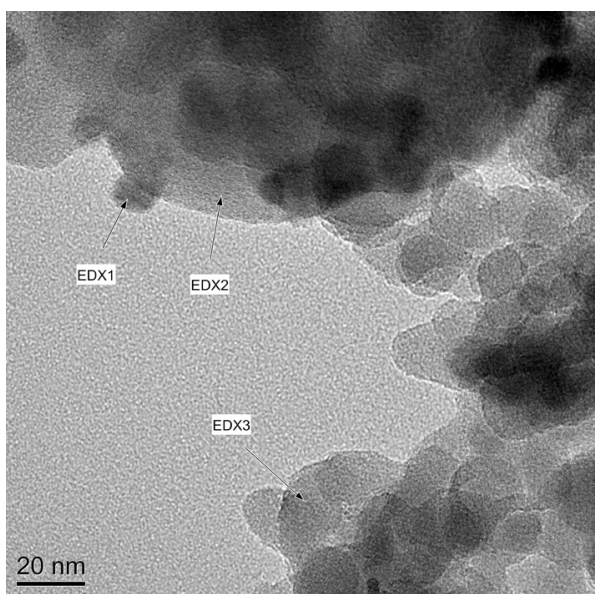

(a)

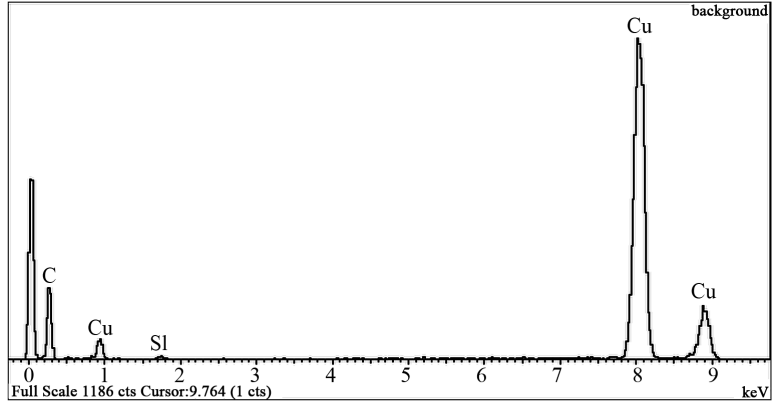

(b)

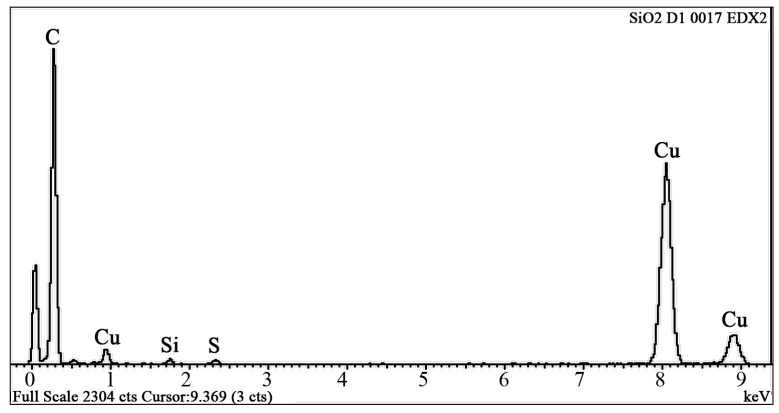

(d)

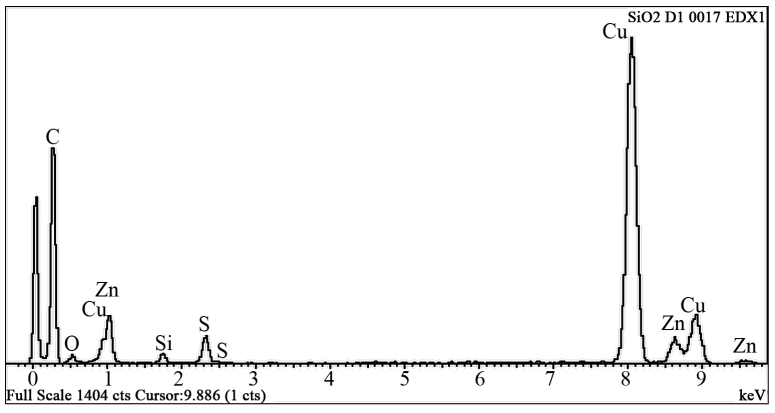

(c)

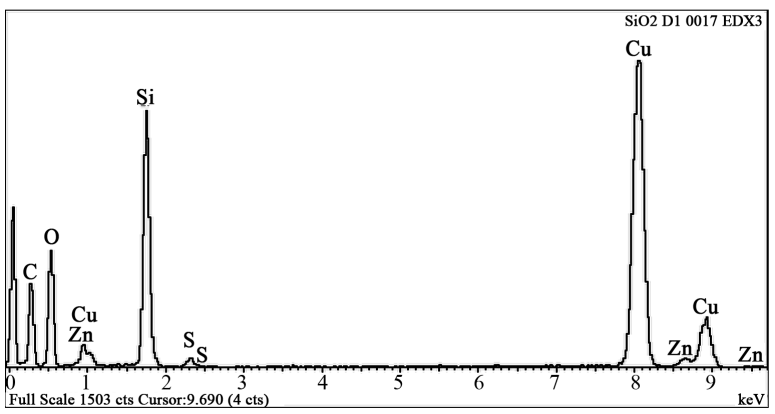

(e)

Figure 9. Energy dispersive spectra on STEM of carbon black-silica filler obtained by pyrolysis of waste green tires: (a) STEM image (annotated); (b) background; (c) EDX1 (ZnS); (d) EDX2 (carbon); (e) EDX3 ( $\mathrm{SiO}_{2}$ ).

Figures 10 and Figure 11.

EDX spectra indicate that there are zones that practically consist of carbon alone $(3,6)$, as well as areas in which carbon and silica coexist and are mixed on a very deep level. It is important to note that areas which contain only carbon are not noticed with the fillers obtained by pyrolysis, i.e. blending of both phases is really on a deeper level there. At that, there is tendency observed with increasing amount of silica in the sample, its quantity in these areas to enlarge too, judging for which by the increased intensity of silicon and oxygen picks (Spectra 7, 4).

It is also obvious that the quantity of introduced silica influences practically all the characteristics of hybrid filler, as it can be seen from Table 3 and Table 4. Research by STEM-EDX shows also its influence on the formation of silica aggregates, their size and placement among the carbon black phase formations. It can be considered, that the silica concentration for obtaining of CSF-10 is more favorable from that point of view because the aggregates of the both phases are comparable and are not well isolated. Characteristics of CSF-10, shown in 


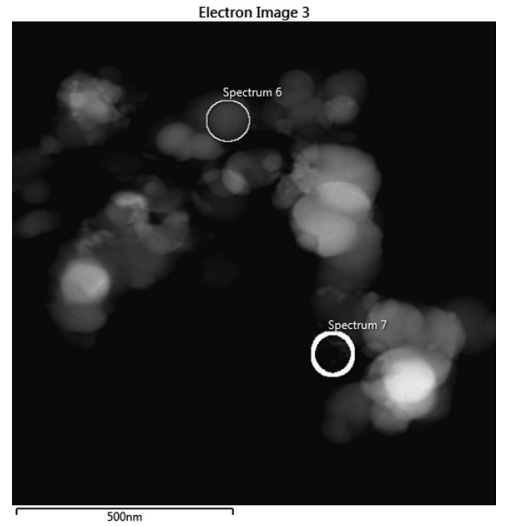

(a)

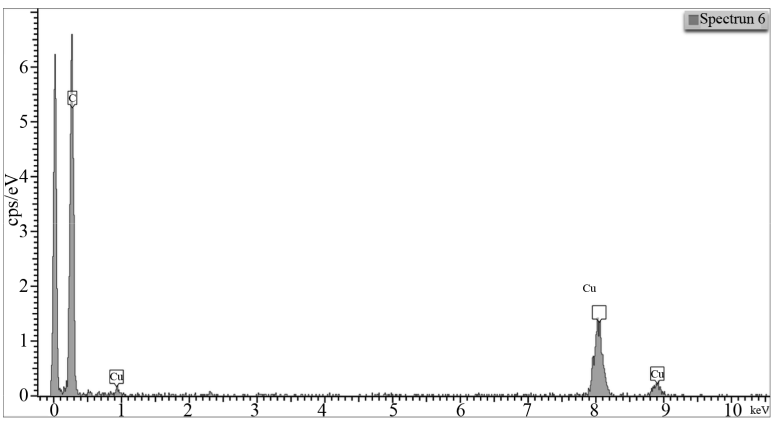

(b)

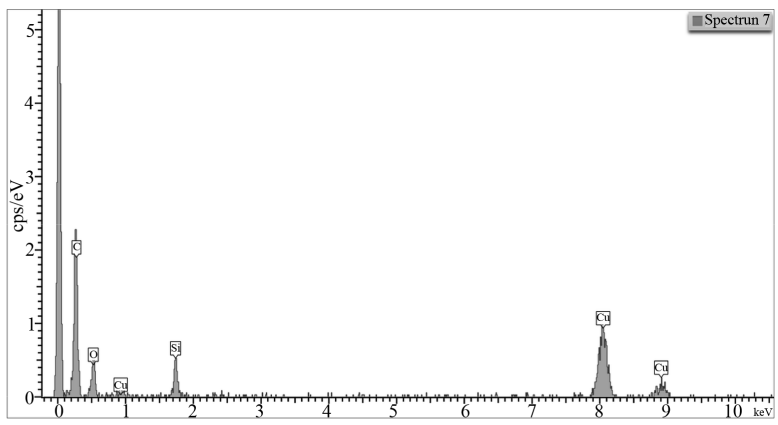

(c)

Figure 10. EDS on STEM of CSF-10 filler: (a) spectra positions; (b) spectrum 6; (c) spectrum 7.

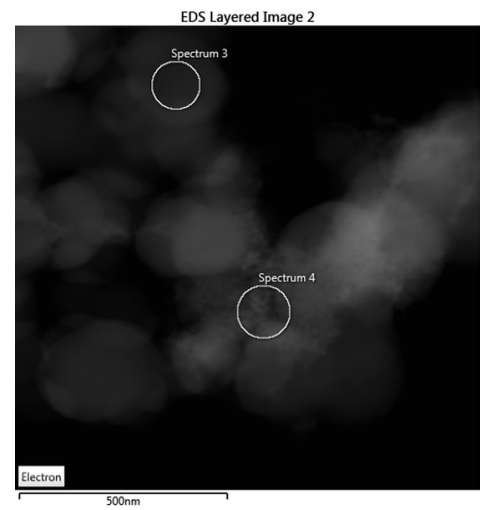

(a)

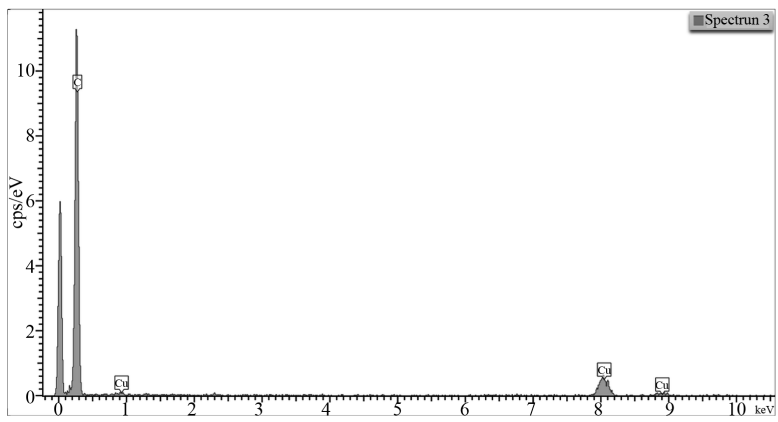

(b)

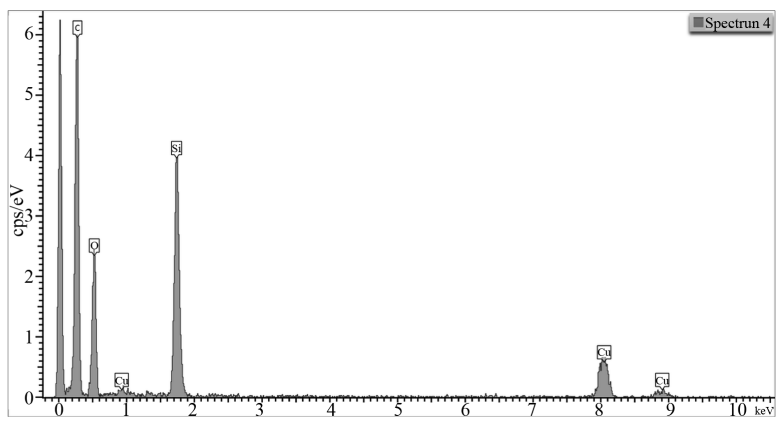

(c)

Figure 11. EDS on STEM of CSF-20 filler: (a) spectra positions; (b) spectrum 3; (c) spectrum 4. 
Table 1 and Table 2 also give precedence to this sample: its specific surface area is not so higher, while at the same time it is characterized by pores with the largest diameter, which creates conditions for the contact of the greatest number of elastomer macromolecules with filler and respectively the best strengthening effect.

\section{Conclusions}

It has been compared the characteristics of hybrid fillers of the type of carbon, silica, obtained by two different methods: via pyrolysis and by impregnation. It was found that the characteristics of the used fillers differ substantially; in some cases they are even opposite, due to contrary approaches for their obtaining.

It is obvious that the creation of dual phase fillers according to the proposed methods is one way, allowing for changes in the desired direction of all important factors affecting the improvement of elastomers: size and specific surface area of the particles, morphology, structure, degree of irregularity, and surface activity.

In most aspects carbon-silica fillers differ from the traditional fillers used as reinforcing agents in the rubber industry. The possibilities they discover to control the interactions "elastomer-filler" and "filler-filler" and from here a number of operational properties of final products (dynamic, mechanical, etc.) can be considered as very perspective.

\section{Acknowledgements}

The present research is a result of an international collaboration program between University of Tabuk, Tabuk, Kingdom of Saudi Arabia and the University of Chemical Technology and Metallurgy, Sofia, Bulgaria. The authors gratefully acknowledge the financial support from the University of Tabuk.

Authors wish also to thank to Dr. Antonia Dimitrova, SPEME, University of Leeds, Leeds LS2 9JT, UK for her assistance in STEM-EDX analyses, as well as to Prof. Ljutzkan Ljutzkanov, Institute of Chemical Engineering, Bulgarian Academy of Sciences, Sofia, Bulgaria, for the preparation of the carbon-silica fillers by pyrolisis.

\section{References}

[1] Frohlich, J., Niedermeier, W. and Luginsland, H.-D. (2005) The Effect of Filler-Filler and Filler-Elastomer Interaction on Rubber Reinforcement. Composites: Part A, 36, 449-460.

[2] Donnet, J.-B. and Custodero, E. (2013) Reinforcement of Elastomers by Particulate Fillers. In: Mark, J.E., Erman, B. and Roland, C.M., Eds., The Science and Technology of Rubber, 4th Edition, Elsevier, Amsterdam, 383-416. http://dx.doi.org/10.1016/B978-0-12-394584-6.00008-X

[3] Mahmud, K., Wang, M.-J. and Francis, R.A. (1998) Elastomeric Compound Incorporating Silicon-Treated Carbon Black. US Patent No. 5830930.

[4] Wang, M.J., Kutsovsky, Y., Zhang, P., Mehos, G., Murphy, L.J. and Mahmud, K. (2002) Using Carbon-Silica Dual Phase Filler Improve Global Compromise between Rolling Resistance, Wear Resistance and Wet Skid Resistance for Tires. Kautschuk Gummi Kunststoffe, 55, 33-40.

[5] Wang, M.J., Mahmud, K., Murphy, L.J. and Patterson, W.J. (1998) Carbon-Silica Dual Phase Filler-A New Generation Reinforcing Agent for Rubber. Kautschuk Gummi Kunststoffe, 51, 348-360.

[6] Kolev, D., Ljutzkanova, R. and Abadjiev, S. (2005) Method and Installation for Pyrolysis of Tires. Bulgarian Patent 65901 B1.

[7] Kolev, D., Ljutzkanova, R. and Abadjiev, S. (2008) Method and Installation for Pyrolysis of Tires. European Patent EP 1879978 A1.

[8] Isayev, A. (2013) Recycling of Rubbers. In: Erman, B., Mark, J. and Roland, C., Eds., The Science and Technology of Rubber, 4th Edition, Elsevier, Amsterdam, 753-755. http://dx.doi.org/10.1016/B978-0-12-394584-6.00020-0

[9] Ivanov, M., Mihaylov, M. and Ljutzkanov, L. (2010) Silica Obtained via Pyrolysis of Waste “Green” Tyres-A Perspective Filler for Rubber Industry. Kautschuk Gummi Kunststoffe, 63, 303-307.

[10] Ivanov, M. and Mihaylov, M. (2011) Silica Obtained via Pyrolysis of Waste “Green” Tyres—A Filler for Tyre Tread Rubber Blends. Journal of Elastomers and Plastics, 43, 303-316. http://dx.doi.org/10.1177/0095244311398636

[11] Al-Hartomy, O.A., Al-Ghamdi, A.A., Al Said, S.A., Dishovsky, N., Mihaylov, M., Ivanov, M. and Ljutzkanov, L. (2013) Effect of the Carbon-Silica Reinforcing Filler Obtained from the Pyrolysis-cum-Water Vapour of Waste Green Tyres upon the Properties of Natural Rubber Based Composites. Progress in Rubber, Plastics and Recycling Technology, in press.

[12] Al-Hartomy, O.A., Al-Ghamdi, A.A., Al-Said, S.A., Dishovsky, N., Mihaylov, M., Ivanov, M. and Ljutzkanov, L. 
(2014) Effect of the Solid Product Obtained by Pyrolysis of Waste Green Tires on the Properties of Epoxidized Natural Rubber Based Composites. International Review of Chemical Engineering, in press.

[13] Al-Hartomy, O.A., Al-Ghamdi, A.A., Al-Said, S.A., Dishovsky, N., Mihaylov, M., Ivanov, M. and Ljutzkanov, L. (2013) Influence of the Carbon-Silica Reinforcing Filler Obtained via Pyrolysis of Waste "Green” Tyres on the Properties of EPDM Based Composites. Kautschuk Gummi Kunststoffe, in press.

[14] Marsh, H., Heintz, E. and Rodrigues-Reinoso, F. (1997) Introduction to Carbon Technologies. University of Alicante, Alicante.

[15] Malinova, P., Nikolov, R., Dishovsky, N. and Lakov, L. (2004) Modification of Carbon-Containing Fillers for Elastomers. Kautschuk Gummi Kunststoffe, 57, 443-445.

[16] Al-Hartomy, O.A., Al-Ghamdi, A.A., Al-Said, S.A., Dishovsky, N., Malinova, P. and Nikolov, R. (2013) Obtaining of Carbon-Silica Dual Phase Filler by Impregnation Method and Investigation of Its Influence on the Properties of SBR Based Composites. Journal of Materials Design and Application, in press.

[17] ISO 15651/1-91.

[18] Bulgarian State Standard 9665:1176.

[19] Brunauer, S., Emmett, P.H. and Teller, E. (1938) Adsorption of Gases in Multimolecular Layers. Journal of the American Chemical Society, 60, 309-319. http://dx.doi.org/10.1021/ja01269a023

[20] ISO 1125:1999.

[21] Ullmann’s Encyclopedia of Chemical Industry, 1999-2014. John Wiley \& Sons Inc.

[22] Dohi, H. and Horiuchi, S. (2007) Heterogeneity of a Vulcanized Rubber by the Formation of a ZnS Clusters. Polymer, 48, 2526-2530. http://dx.doi.org/10.1016/j.polymer.2007.03.004

[23] Ramesan, M.T., Nihmath, A. and Francis, J. (2013) Preparation and Characterization of Zinc Sulphide Nanocomposites Based on Acrylonitrile Butadiene Rubber. Proceeding of International Conference on Recent Trends in Applied Physics \& Material Science RAM 2013, Bikaner, 1-2 February 2013, 255-256.

[24] David, S., Fritzen, P., Heiming, L. and Rentschler, T. (2010) Plastic Comprising ZnS. US Patent No. 8383712. 
Scientific Research Publishing (SCIRP) is one of the largest Open Access journal publishers. It is currently publishing more than 200 open access, online, peer-reviewed journals covering a wide range of academic disciplines. SCIRP serves the worldwide academic communities and contributes to the progress and application of science with its publication.

Other selected journals from SCIRP are listed as below. Submit your manuscript to us via either submit@scirp.org or Online Submission Portal.
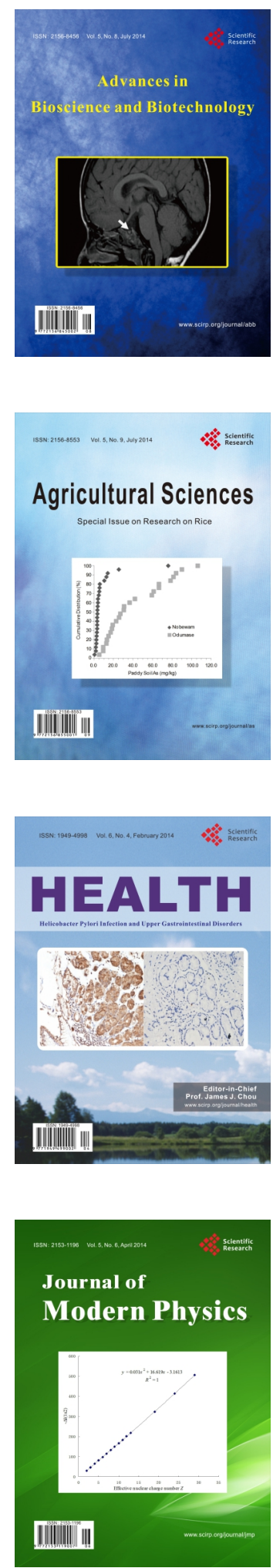
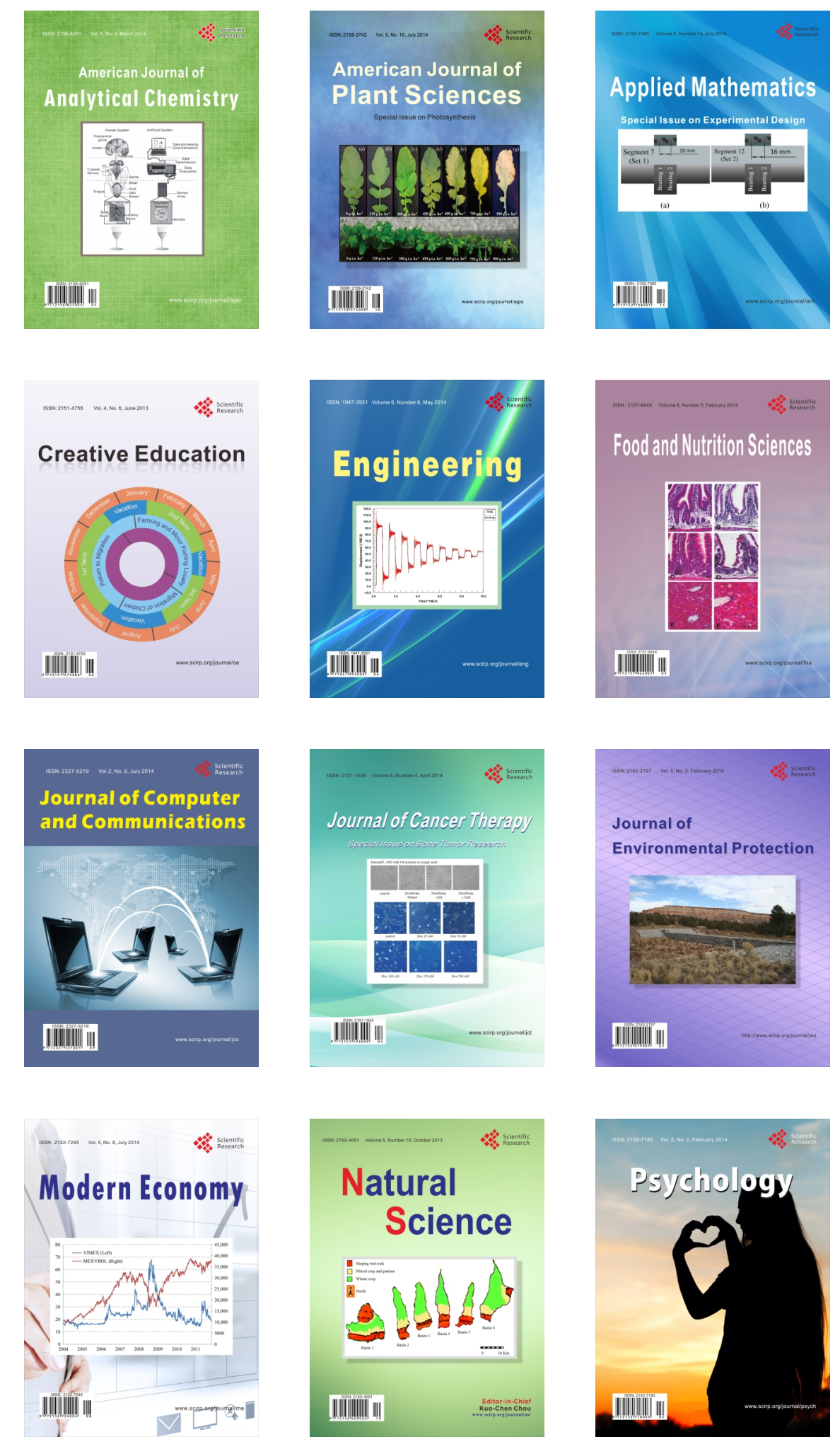